\title{
A Review of Literature on Social Media and Acculturation
}

\author{
Kankan Wen \\ Endicott College of International Studies, Woosong University, Daejeon, Republic of Korea \\ Email: 201880280@live.wsu.ac.kr
}

How to cite this paper: Wen, K. K. (2020). A Review of Literature on Social Media and Acculturation. Open Journal of Social Sciences, $8,19-29$.

https://doi.org/10.4236/jss.2020.86002

Received: May 8, 2020

Accepted: May 30, 2020

Published: June 2, 2020

Copyright (C 2020 by author(s) and Scientific Research Publishing Inc. This work is licensed under the Creative Commons Attribution International License (CC BY 4.0).

http://creativecommons.org/licenses/by/4.0/

(c) (i) Open Access

\begin{abstract}
With the development of populous mobility and digital technology, integration of acculturation and social media, which is represented by Social Networking Sites (SNSs), is increasingly focused on by academia. With the keyword selection, 34 articles were collected. The structured content analysis was adopted to conduct the review via mapping, assessing, and synthesizing the articles. It was found that acculturation and related topics are closely related to social media. Specifically, the integration of SNSs and acculturation is the trend of present and future research. The research gaps based on the literature are also proposed for future studies.
\end{abstract}

\section{Keywords}

Acculturation, Acculturative Stress, Social Media, Social Networking Sites, Sojourners

\section{Introduction}

With the development of globalization, it has been commonplace for people to sojourn abroad for purposes of work or study. The sojourners include immigrants, expatriates, refugees, international students, etc., according to classification in general. Researches (Geeraert \& Demoulin, 2013) show that, as with other forms of international mobility, the process of acculturating into the new environment is essential for working or studying abroad. When exposure to a foreign country, interacting and getting contact with another culture frequently over time, acculturation arises (Berry \& Sabatier, 2011). Acculturation has been a sustainable object for international studies in the field of sociology, psychology, and management, etc. It has been estimated that there are currently 50 million expatriates and include more than 5 million international students worldwide (ICEF Monitor, 2017). In 2030, it is estimated by Study portals that there will be 
$51 \%$ more students studying in higher education institutions outside their own countries than that in 2015 (so an additional 2.3 million students to total 6.9 million tertiary students abroad in 2030) (ICEF Monitor, 2019). It is natural and inescapable for sojourners in host cultures. Therefore, it deserves studying this prevalent international phenomenon, in which acculturation is one of the most significant parts.

With the advances of digital information and web technologies, especially $4 \mathrm{G}$ technology, it has dramatically boosted the development and application of social media platforms represented by Social Networking Sites (Afterwards SNSs) in a big scope of fields. After the 2010s, social media, especially SNSs has been broadly used in practice. Easier access to the Internet and increasing multiple demands facilitated the formation of online communities in social media, which fostered the emergence of the online cultures with their corresponding behavior and language practices (Mitra \& Evansluong, 2019). Using Social media platforms, especially SNSs to stay connected to family, friends, and other online users is considered as an important part of many individuals' daily life when they are exposed to new cultures (Eslami \& Yang, 2018). Some popular SNSs, such as Myspace, Twitter, Weibo, WeChat, and Facebook, attract numerous users of different nationalities. Maintaining relationships with family and friends, communicating thoughts and activities, and meeting new individuals are primary functions of SNSs. As of March 2017, there were over 1.94 billion monthly-active, Facebook users (Facebook MAUs), which is an $18 \%$ increase, year over year (Facebook 5/3/17).

\section{Acculturation and Social Media}

Acculturation refers to "those phenomena which result in when groups of individuals having different cultures come into continuous first-hand contact, with subsequent changes in the original cultural pattern of either or both groups " ( $R$. Redfield, R. Linton, and M. Herskovits, 1936). It is possibly the earliest definition of acculturation (Tranfield, Denyer, \& Smart, 2003). They described acculturation as a process that occurs when groups of different cultures brought together in contact and which consequently leads to changes in the cultural patterns. Although acculturation is a neutral term in principle (that is, change may take place in either or both groups), acculturation in practice tends to induce more change in one of the groups than in the other (Berry \& Sabatier, 2011).

Social media, especially SNSs, as online services to build social relations among people who communicate with each other, have rapidly become a global consumer phenomenon (Huang, Hsieh, \& Wu, 2014). Several popular SNSs, such as Facebook, Snap Chat, Twitter, Kaokao Talk in Korea, and WeChat in China, are widely used among teenagers and young adults, as they provide an open platform for these individuals to communicate, produce and exchange information such as pictures, videos, interests, and preferences (Milosevic-Dordevic \& Žeželj, 2014).

With the development of both populous mobility and digital technology, there 
emerged more and more researches focusing on the integration of acculturation and social media or SNSs. To shed some light on the relationship between acculturation and social media or SNSs and investigating the status quo of the research on this topic systematically to identify the research gap for future studies. We need to conduct a systematic literature review research by addressing the following research questions:

RQ1. What is the status quo of the research on the integration of acculturation and social media or SNSs?

RQ2. What is the relationship between acculturation and social media or SNSs in present research?

To answer the above two research questions, we conducted a systematic literature review focused on acculturation and social media or SNSs in the present literature. Systematic literature reviews are appropriate for mapping, assessing, and synthesizing different pieces of literature to develop the knowledge base in a field (Tranfield et al., 2003). Therefore, the literature review article was selected to research the following sections.

\section{Methodology}

This article aims to analyze the relationships between acculturation and social media especially SNSs and investigate the status quo of the research on this topic systematically, and more importantly to identify the research gap for future studies. We accomplish this aim by conducting a systematic literature review based on structured content analysis. Tranfield et al. (2003) argue that there are two goals for literature reviewing: to consolidate research findings in a specific field by mapping, assessing and synthesizing different pieces of literature and identifying research gaps for future studies. Evidence is important in the literature review considering it supports the collection and analysis of materials to reach transparent and reliable outcomes. To further elaborate on our literature review, we apply structured content analysis as suggested by some scholars (Seuring \& Gold, 2012). Structured content analysis is a commonly adopted method for systematically assessing the themes of recorded communication. It is employed for conducting literature reviews because it provides a sound understanding of the focus of written text in a rule-governed manner, thus replicability can be accomplished as well (Seuring \& Gold, 2012).

According to Seuring and Gold (2012), a four-step process for conducting literature reviews based on structured content analysis is reasonable. The four steps include material collection, descriptive analysis, category identification, and material evaluation. The following sections will follow the four steps. After searching the literature, the multi-sectional analysis was employed to analyze. A variety of figures, charts, and tables were used to illustrate the contrasts and comparisons so that the outcomes can show clearly.

\section{Results}

Through the database ScienceDirect and Scopus, combined with sorting of 
ABDC journal ranking, with putting the keyword "acculturation", "cross-cultural adaption", "inter-cultural adaption", plus "social media" "social networking sites/services" "SNSs" in English, totally 34 peer-reviewed English articles were found in titles including the said keywords. To analyze and conclude these articles were downloaded and categorized according to different norms and catenaries, such as the year published, focused areas, geographic focus, the method adopted, etc., some figures and graphs were produced automatically with the help of Excel and relevant statistical software.

There are not many articles relevant to acculturation and social media or SNSs. One possible reason may be that social media, especially SNSs is a newly emerged thing, started from the 2010s, just as stated in the introduction part. It has a process for sojourners to use; then it also takes time for academics to study the phenomenon.

Exactly, as Figure 1 indicates, the first article on the topic was published in 2005 when it is the unique published article. Until in 2011, the second article was published, and there were 3 articles published in total. From the year 2013 to the year 2019, there were at least 2 articles published per year. Among these years, in 2019, there were 10 articles published, noting that the newest article was published in September 2019. It is a dramatic increase in number compared with the former years, among which there were 5 articles published in 2015 .

As for geographic location, it is imbalanced. As Figure 2 shows, USA is the most intensively studied geographic country with 16 articles focused, accounting for 47\%; other focused countries include China with 6 articles, Republic Korea, Netherlands, UK, Malaysia, Japan and Australia followed in sequence of degree of studied density.

As we consider the years on which the researches were focused, we can find, as Figure 3 indicates, that it is varied accordingly. Among the years from the year of 2002 to 2018 , the year of 2018 was targeted by 8 articles, followed by the year of 2014 in which 5 articles was concerned. And 4 articles in 2012 and 2 in 2010 were focused.

The methodology adopted among these articles is classified into 3 categories: quantitative method, qualitative method, and mixed-method, as Figure 4 indicates. 27 articles are employing a quantitative method which makes up 79.4\%, while 4 articles with a qualitative method and 3 articles with a mixed method.

Journals in which the articles were published are also analyzed, as Figure 5 shows below. Among the journals, Technological Forecasting \& Social Change, and Computer in human behavior were the priority choices with 7 articles each, 5 articles were published in the journal Internal Journal of Intercultural Relations, 3 articles are the thesis for master's degree; The rest of 11 articles were dispersed in 11 other different journals.

As stated in the theoretical framework part, acculturation and acculturative stress were initially focusing on immigrants in some western countries, such as Canada and the USA. As time went by, researches started to paid attention to 


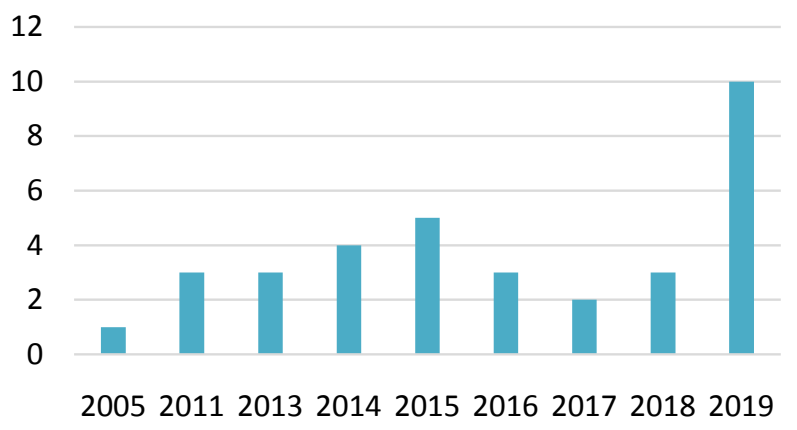

Figure 1. Number of the articles published yearly.

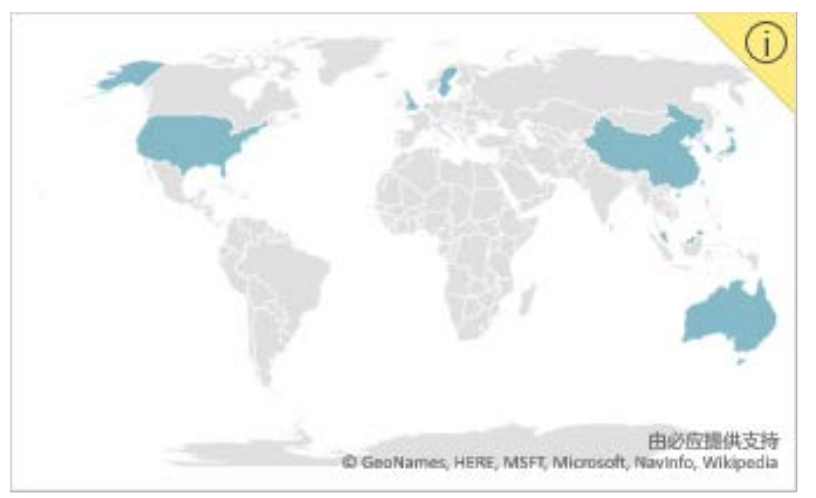

Figure 2. The geographical focus of the articles published.

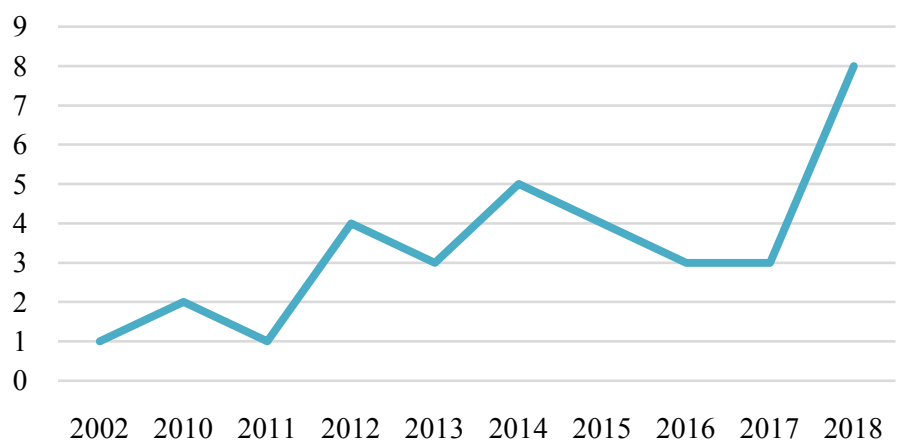

Figure 3. Years analyzed of the articles published.

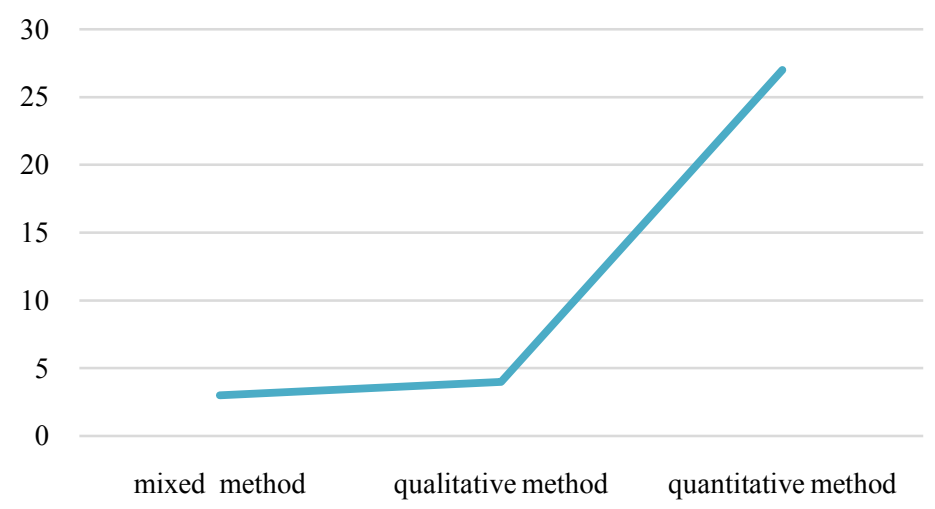

Figure 4. Methods adopted of relevant articles published. 
- Technological Forecasting \& Social

Change

- Computers in human behavior

- International Journal of Intercultural

Relations

Figure 5. Journals where relevant articles published.

other sojourners, such as international students, international workers, refugees, and other groups (Hofhuis, Hanke, \& Rutten, 2019). Figure 6 shows that among aforesaid 34 articles, $74 \%$ of the researches focused on international students, $26 \%$ of which on other sojourners.

Social media and SNSs are closely related in a variety of aspects, with many similarities and some differences, just as stated in the definition part. With relevant information technology advancements, SNSs have been becoming increasingly prevalent and popular owing to its strong function and friendly application (Janssen, n.d.). According to Figure 7, among the 34 articles, 79.4\% with 27 articles are related to SNSs as their either independent variable or dependent variable.

The theories employed are varied, which was indicated in line with the key-dependent variables, independent variables, authors of the articles, years in Table 1. We can find that Berry's acculturation theory is the most popular theory, which was adopted in 13 articles, followed by Hofstede's' collectivism vs individualism in 3 articles. We also find that among key dependent variables, acculturation is the most common one; while among key independent variables, that is SNSs, followed by social media.

From Table 1, it is unambiguous that under Berry's acculturation theory dependent variable acculturation and its related acculturative stress and cross-cultural adaption are closely relevant with the key independent variables SNSs and social media. We can find that Berry's acculturation theory employed in 13 articles is the absolute theory in acculturation. We found that that dependent variable and independent variable are the same as Table 1 . However, the theories employed are varied, among which Hofstede's' collectivism vs individualism is mostly adopted in three articles. The result reveals that acculturation (cultural adaption and acculturative stress) is closely related to the use of social media or SNSs for all sorts of sojourners in a variety of settings. 


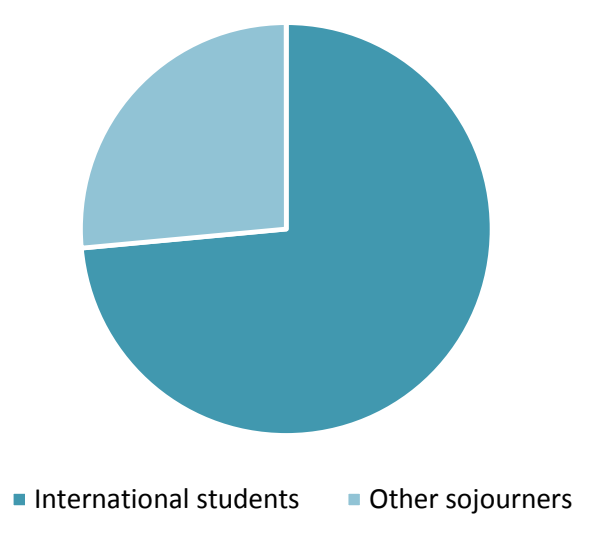

Figure 6. The object of study among the articles.

25

20

15

10

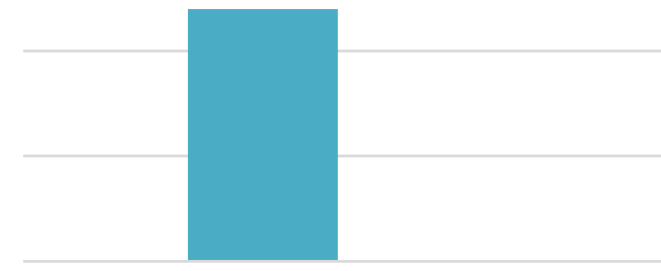

social media

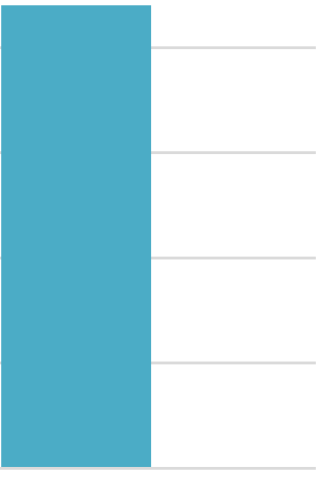

SNSs

Figure 7. Variables concerned among the articles.

Table 1. Main theory and related variables and other information.

\begin{tabular}{|c|c|c|c|c|}
\hline Theory & Key dependent variables & $\begin{array}{l}\text { Key independent } \\
\text { variables }\end{array}$ & Author & Year \\
\hline \multirow{12}{*}{$\begin{array}{l}\text { Berry's } \\
\text { Acculturation theory }\end{array}$} & acculturation & social media & A Mitra, Q Evansluong & 2019 \\
\hline & acculturation & social media & C Li, S Guo, CL Wang, J Zhang & 2019 \\
\hline & acculturative stress and social connectedness & SNSs & D Fread & 2014 \\
\hline & socialization and political engagement & SNSs & H Kizgin, A Jamal, N Rana, Y Dwivedi & 2019 \\
\hline & acculturation & SNSs & J Hofhuis, K Hanke, T Rutten & 2019 \\
\hline & social support and acculturative stress & SNSs & L Li, W Peng & 2019 \\
\hline & social networks & SNSs & E Forbush, B Foucault-Welles & 2016 \\
\hline & cross-cultural adaption & SNSs & RB Gillie & 2016 \\
\hline & acculturation & social support & TK Ng, KWC Wang, W Chan & 2017 \\
\hline & acculturation & SNSs & Q Yu, P Foroudi, S Gupta & 2019 \\
\hline & acculturation & social media & S Choudhary, R Nayak, S Kumari & 2019 \\
\hline & acculturation & social media & W Wang, I Abosag & 2019 \\
\hline
\end{tabular}




\section{Conclusion}

We can conclude from the above sections by systematically mapping, collecting, analyzing, and synthesizing the mentioned literature (Koberg \& Longoni, 2019). For the different numbers of articles published in different years, one of the possible causes for the dramatic increase of the articles published in 2019 is that the research on the integration of acculturation and social media especially SNSs is still hot and popular, though it is a new research topic recently (Hofhuis et al., 2019). Also, deduced from Figure 2 and Figure 6, the number of international students has been surging since the new century, and some countries in North America, west Europe, East Asia have been or are becoming the major destinations of international students' mobility. Therefore, it is likely that their acculturation and related issues give rise to academics' attention and interests. One phenomenon that a curve exists in the period from 2015 to 2019 was not delivered a reasonable explanation until now. Deducing from Figure 3, the dramatic changes of years focused, the possible reason for some year was focused that may be interpreted that some factors, such as new technologies, political policies, affect the changes.

Regarding the distribution of geography, we judge that one cause for the unbalanced distribution of geographic focus of the research may be that the USA is a traditional and ongoing destination of population mobility, especially for international students. Moreover, the USA and China are the original and emerging centers of digital technology, where most IT giants such as Facebook, Twitter, WeChat, and Tiktok are located. Therefore, SNSs and other social media platforms are prevalent in these areas (Hofhuis et al., 2019).

The methodology is unambiguous in the mentioned literature. In terms of acculturation and social media or SNSs, a measurement that can be accomplished is one of the reasons that the quantitative method is mostly employed in the research. Also, there have been some available Metrix, scales, and questionnaires which were developed by some scholars and were verified to be reliable and valid in the field of acculturation and diffusion of social media. Considering the integration with technology, Technological Forecasting \& Social Change was the preferred journal for this study and its researchers.

International students have been a major temporary sojourner with the rapid development of globalization of economy, technology, and talent. And the international students are vulnerable to acculturation, more stressed; therefore, they may be focused by academia more than other sojourner groups. One more possible reason is that international students are more active and professional in using social media and SNSs; moreover, it is necessary for them to communicate with their parents, friends, and others to buffer their acculturative stress (Yu, Foroudi, \& Gupta, 2019). Compared with other traditional social media, such as newspapers and TV, SNSs are becoming more and more popular for its multiple strengths as mentioned in the introduction part.

In terms of theories employed in literature, Berry's acculturation theory is the 
dominant one, followed by Hofstede's' collectivism vs individualism. Also, from dependent and independent variables, the most commonly used are acculturation and SNSs. Partly, it is because the keywords put for searching are acculturation and SNSs or social media.

\section{Discussion and Implications for Future Research}

There are some implications. The mentioned articles were all published recently, which implies the trend of the research in the area to some degree. From the figures, charts, and tables, as well as the above sections, we can foresee the following contents and perspectives may be the trends and hot subtopics in future research. It is predicted that in future the research on the integration of acculturation and SNSs, and other related topics will still be the interests of academia in this field, considering the gap that the status quo is and how it works regarding the integration of acculturation and SNSs in other countries, especially in developing countries. One more reason is that with the rapid economic development, developing countries are increasingly focusing on the development and application of digital information.

I am aware that the research has some limitations. Just as many literature reviewing papers, a keyword search was adopted for the review, which may affect and limit the results owing to combinations of keywords. A second limitation is the researcher's biases when the author selects current relevant articles. A third limitation is that there is only one author who may arouse some mistakes or neglects, and even bias. Subjectivity is another limitation for the research considering the method structured content analysis used and the criteria for the article were set subjectively, without former studies. Also, only peer-reviewed papers are selected without considering other sources such as conference papers, Ph.D. degree thesis, and industrial reports. Finally, in the topic integration of acculturation and social media or SNSs, three keywords are all broad with many different definitions, demarcations, and categories, therefore the research may not be accurate to some extent. Nonetheless, we still believe this review makes some contributions to the knowledge of acculturation and its integration with related digital technology.

Broadly speaking, the research is a cross-disciplinary study related to technology, sociology, psychology, culture, and management. Therefore, in the future, it is suggested editors of relevant journals related to be said disciplinaries can consider accepting more articles concerning the integration of acculturation and social media or SNSs. Also, more qualitative and mixed methods are suggested to adopt to supplement and enrich the research from the disparate lens of research. Besides, maybe more attention should be concentrated on other less populous sojourners, such as migrants, refugees, and tourists. The number of these sojourners is also growing fast these years, especially international tourists. Finally, the researchers may focus on more SNSs' roles and effects on acculturation and related topics in that SNSs is ongoing, full of more imagination and 
possibilities in the future.

\section{Funding}

The author received no financial support for the research, authorship, and/or publication of this article.

\section{Conflicts of Interest}

The author declared no potential conflicts of interest with respect to the research, authorship, and publication of this article.

\section{References}

Berry, J. W., \& Sabatier, C. (2011). Variations in the Assessment of Acculturation Attitudes: Their Relationships with Psychological Wellbeing. International Journal of Intercultural Relations, 35, 658-669. https://doi.org/10.1016/j.ijintrel.2011.02.002

Eslami, Z. R., \& Yang, X. (2018). Chinese-English Bilinguals' Online Compliment Response Patterns in American (Facebook) and Chinese (Renren) Social Networking Sites. Discourse, Context \& Media, 26, 13-20. https://doi.org/10.1016/j.dcm.2018.04.006

Geeraert, N., \& Demoulin, S. (2013). Acculturative Stress or Resilience? A Longitudinal Multilevel Analysis of Sojourners' Stress and Self-Esteem. Journal of Cross-Cultural Psychology, 44, 1241-1262. https://doi.org/10.1177/0022022113478656

Hofhuis, J., Hanke, K., \& Rutten, T. (2019). Social Network Sites and Acculturation of International Sojourners in the Netherlands: The Mediating Role of Psychological Alienation and Online Social Support. International Journal of Intercultural Relations, 69, 120-130. https://doi.org/10.1016/j.ijintrel.2019.02.002

Huang, L. Y., Hsieh, Y. J., \& Wu, Y. C. J. (2014). Gratifications and Social Network Service Usage: The Mediating Role of Online Experience. Information and Management, 51, 774-782. https://doi.org/10.1016/j.im.2014.05.004

ICEF Monitor (2017). ICEF Monitor-Market Intelligence for International Student Recruitment. http://monitor.icef.com

ICEF Monitor (2019). ICEF Monitor-Market Intelligence for International Student Recruitment.

https://monitor.icef.com/2019/08/international-students-generate-global-economic-im pact-of-us300-billion/

Janssen, C. (n.d.). What Is a Social Networking Site (SNS)? - Definition from Techopedia. http://www.techopedia.com/definition/4956/social-networking-site-

Koberg, E., \& Longoni, A. (2019). A Systematic Review of Sustainable Supply Chain Management in Global Supply Chains. Journal of Cleaner Production, 207, 1084-1098. https://doi.org/10.1016/j.jclepro.2018.10.033

Milosevic-Dordevic, J. S., \& Žeželj, I. L. (2014). Psychological Predictors of Addictive Social Networking Sites Use The Case of Serbia. Computers in Human Behavior, 32, 229-234. https://doi.org/10.1016/j.chb.2013.12.018

Mitra, A., \& Evansluong, Q. (2019). Narratives of Integration: Liminality in Migrant Acculturation through Social Media. Technological Forecasting and Social Change, 145, 474-480. https://doi.org/10.1016/j.techfore.2019.01.011

Seuring, S., \& Gold, S. (2012). Conducting Content-Analysis Based Literature Reviews in Supply Chain Management. Supply Chain Management, 17, 544-555. 
https://doi.org/10.1108/13598541211258609

Tranfield, D., Denyer, D., \& Smart, P. (2003). Towards a Methodology for Developing Evidence-Informed Management Knowledge by Means of Systematic Review. British Journal of Management, 14, 207-222. https://doi.org/10.1111/1467-8551.00375

Yu, Q., Foroudi, P., \& Gupta, S. (2019). Far Apart yet Close by: Social Media and Acculturation among International Students in the UK. Technological Forecasting and Social Change, 145, 493-502. https://doi.org/10.1016/j.techfore.2018.09.026 